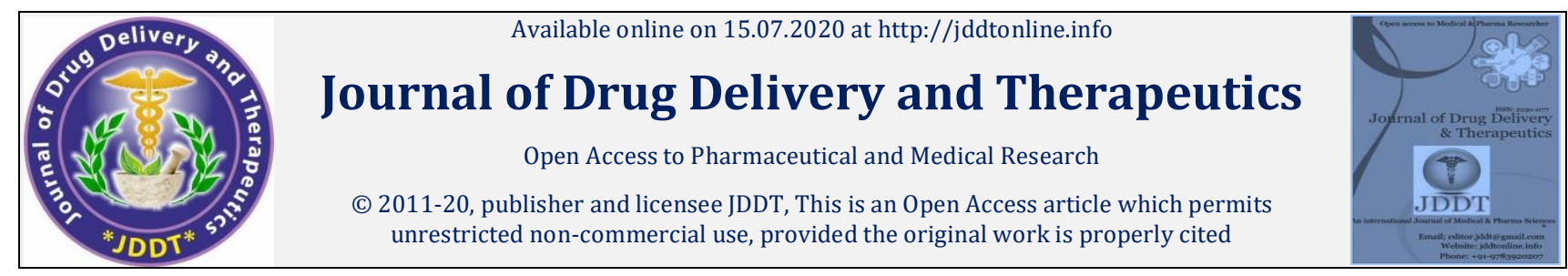

Open $\odot$ Access

Research Article

\title{
Acute Toxicity Study of Aqueous Extracts of Thymelaea hirsuta Leaves And Flowers in Rabbits
}

\section{Mounira Merghem*, Saliha Dahamna and Seddik Khennouf}

Laboratory of Phytotherapy Applied to Chronic Diseases, Department of Biology and Animal Physiology, Faculty of Natural and Life Sciences, Ferhat Abbas University, Sétif, Algeria

\begin{abstract}
Thymelaea hirsuta is a medicinal plant known for its therapeutic virtues in traditional medicine. The objective of this study was to evaluate the acute toxicity of aqueous extract of leaves and flowers of Thymelaea hirsuta in rabbit. Aqueous extract was administered to rabbit in single doses of 2.5, 4, 5.5 and $7 \mathrm{~g} / \mathrm{kg}$ given by gavage. General behavior, adverse effects and mortality were determined for up to 7 days. Biochemical parameters aspartate aminotransferase (AST), alanine aminotransferase (ALT), alkaline phosphatase (ALP), cholesterol (CHOL) and glucose (GLU) were determined after 7 days. The results showed no mortality was observed during the 7 days of the observation period, an increase in AST and ALT in treated groups at the doses of 4, 5.5 and $7 \mathrm{~g} / \mathrm{kg}$, and a decrease in both cholesterol and glucose levels in treated groups compared to control.
\end{abstract}

Keywords: Thymelaea hirsuta, Acute toxicity, Biochemical parameters, adverses effects.

Article Info: Received17 April 2020; Review Completed 20 June 2020; Accepted 26 June 2020; Available online 15 July 2020

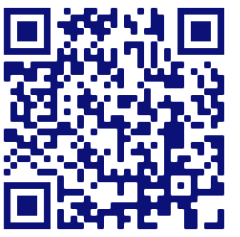

Cite this article as:

Merghem M, Dahamna S, Khennouf S, Acute Toxicity Study of Aqueous Extracts of Thymelaea hirsuta Leaves And Flowers in RabbitS, Journal of Drug Delivery and Therapeutics. 2020; 10(4):67-69 http://dx.doi.org/10.22270/jddt.v10i4.4141

*Address for Correspondence:

Mounira Merghem, Laboratory of Phytotherapy Applied to Chronic Diseases, Department of Biology and Animal Physiology, Faculty of Natural and Life Sciences, Ferhat Abbas University, Sétif, Algeria

\section{INTRODUCTION}

Medicinal plants have been in use all over the world to treat various diseases including inflammation, heart diseases, cancer, etc. Today the large numbers of drugs in use are derived from plants, which are rich in secondary metabolites and essential oils of therapeutic importance. The important advantages claimed for therapeutic uses of medicinal plants in various ailments are their safety besides being economical, effective and their easy availability 1 .

Phytotheraputic products are many times, mistakenly regarded as safe because they are natural ${ }^{2}$. Nevertheless, these products contain bioactive principles with potential to cause adverse effect ${ }^{3}$. Therefore, it is important to evaluate the adverse effects of all the natural products used in therapeutics.

Thymelaea hirsuta a perennial, evergreen and dioecious shrub, which is native to North Africa. Thymelaea hirsuta is a widespread invasive weed and is commonly known as "Methnane". Along the history, Thymelaea hirsuta, family Thymelaeaceae, has been recognized as an important medicinal plant. Much research has been carried out on the medical applications of Methnane 4 .

Thymelaea hirsuta has been used in folk medicine as antiseptic, antimelanogenesis 5, 6, and antioxidant 7 properties. It was shown that the aqueous extract of Thymelaea hirsuta possesses both hypoglycemic and antidiabetic effects in normoglycemic and streptozotocin induced diabetic rats ${ }^{8}$.

This plant contains polyphenols with a substantial part of flavonoids, diterpens that can explain its different pharmacological activities. Hirseins A and B, two daphnane diterpenoids, isolated from Thymelaea hirsuta were found to inhibit melanogenesis in B16 murine melanoma cells $\left[{ }^{9}\right.$.

\section{MATERIALS AND METHODS}

Plant material

Thymelaea hirsuta plant material was collected from Wilaya of Sétif Northeast of Algeria. 


\section{Animal material}

15 rabbits weighing between 800 and $900 \mathrm{~g}$ were used for acute toxicity. The animals were kept in the animal house of the faculty of Nature and Life Sciences, University of Sétif, at a temperature of $20^{\circ} \mathrm{C}$ and a photoperiod cycle of 12 hours light/dark. The animals were housed in cages (3 rabbit per cage) and had free access to standard commercial diet and tap water.

\section{Preparation of aqueous extract}

The leaves and flowers of Thymelaea hirsuta were washed in running water, dried and powdered. $100 \mathrm{~g}$ of powder was mixed with $1 \mathrm{~L}$ of boiled distilled water $\left(100{ }^{\circ} \mathrm{C}\right)$ and was placed at room temperature during $72 \mathrm{~h}$, The resulting mixture was filtered and then evaporated in rotary vacuum evaporator at $45^{\circ} \mathrm{C}$.

\section{Acute toxicity study}

The animals were divided into five groups with 3 animals. The control group was given normal saline. The other groups were given a single dose of $2.5,4,5.5$ and $7 \mathrm{~g} / \mathrm{kg}$ of aqueous extract respectively. The animals were fasted $(8 \mathrm{~h})$ with free access to water prior to administration of the extract dissolved in distilled water. The general behavior of the rabbit was continuously monitored after dosing, periodically during the first $24 \mathrm{~h}$ (with special attention given during the first 4 hours), and then daily thereafter, for a total of 7 days.

At the end of the treatment, animals were fasted overnight, but allowed access to water and libitum. They were subsequently anesthetized with diethyl ether and blood samples were obtained from the heart and collected in tube containing heparin and centrifuged at $4000 \mathrm{r} / \mathrm{min}$ at $4^{\circ} \mathrm{C}$ for 15 minutes to obtain plasma for biochemical analysis.

\section{Blood analysis}

biochemical analysis was performed using an automatic analyzer (Beckman). Parameters included: aspartate aminotransferase (AST), alanine aminotransferase (ALT), alkaline phosphatase (ALP), cholesterol and glucose.

\section{Statistical analysis}

The results are expressed as the mean value \pm standard deviation. One-way analysis of variance followed by the Tukey test was performed to assess differences between groups. Differences were considered significant at $\mathrm{p}<0.05$. Statistical analyses were performed with the aid of the software GraphPad Prism 5®.

\section{RESULTS AND DISCUSSION}

\section{Mortality and signs of toxicity}

The results of the acute toxicity study of Thymelaea hirsuta given orally as single doses are presented in Table 1 . No mortality was observed during the 7 days of the observation period after administration of aqueous extract of Thymelaea hirsuta at the doses of $2.5,4,5.5$ and $7 \mathrm{~g} / \mathrm{kg}$ of body weight. According to Hodge and Sterner 10 , substances with $\mathrm{LD}_{50}$ higher than $5 \mathrm{~g} / \mathrm{kg}$ by oral route are regarded as being safe or practically nontoxic. The signs of toxicity such as diarrhea and Anorexia were observed at the doses of 5.5 and $7 \mathrm{~g} / \mathrm{kg}$ of body weight.

Table 1. Mortality and toxic effects of leaves and flowers aqueous extract of Thymelaea hirsuta.

\begin{tabular}{|c|c|c|}
\hline $\begin{array}{c}\text { Dose } \\
(\mathrm{g} / \mathrm{kg})\end{array}$ & $\begin{array}{c}\text { Death } \\
(\mathrm{D} / \mathrm{T})\end{array}$ & Adverse effects \\
\hline 0 & $0 / 3$ & None \\
\hline 2.5 & $0 / 3$ & None \\
\hline 4 & $0 / 3$ & Anorexia, diarrhea \\
\hline 5.5 & $0 / 3$ & Anorexia, diarrhea \\
\hline 7 & $0 / 3$ & \\
\hline
\end{tabular}

T : total ; D : death

\section{Biochemical analysis}

The values for the biochemical parameters in treated and control animals are presented in Table 2.

Table 2 : Effect of leaves and flowers aqueous extract of Thymelaea hirsuta. on biochemical parameters.

\begin{tabular}{|l|l|l|l|l|l|}
\hline Parameters & Control & $2.5 \mathrm{~g} / \mathrm{kg}$ & $4 \mathrm{~g} / \mathrm{kg}$ & $5.5 \mathrm{~g} / \mathrm{kg}$ & $7 \mathrm{~g} / \mathrm{kg}$ \\
\hline ALT (UI/L) & $38.66 \pm 3.51$ & $45.06 \pm 5.36 \mathrm{~ns}$ & $60.66 \pm 3.51^{*}$ & $58.46 \pm 1.15^{*}$ & $55.8 \pm 15.95^{*}$ \\
\hline AST (UI/L) & $98 \pm 4.58$ & $83.66 \pm 14.36 \mathrm{~ns}$ & $138.5 \pm 37.45^{* *}$ & $186 \pm 35.54^{* * *}$ & $164.53 \pm 46.6^{* * *}$ \\
\hline CHOL (g/L) & $1.12 \pm 0.25$ & $0.42 \pm 0.08^{*}$ & $0.54 \pm 0.06^{*}$ & $0.55 \pm 0.06^{*}$ & $0.49 \pm 0.11^{*}$ \\
\hline GLU (g/L) & $1.21 \pm 0.31$ & $0.62 \pm 0.04^{*}$ & $0.76 \pm 0.07 \mathrm{~ns}$ & $0.79 \pm 0.03 \mathrm{~ns}$ & $0.65 \pm 0.13^{*}$ \\
\hline ALP (UI/L) & $40.33 \pm 6.81$ & $33 \pm 2 \mathrm{~ns}$ & $47.33 \pm 3.8 \mathrm{~ns}$ & $56 \pm 2.65 \mathrm{~ns}$ & $55.66 \pm 12.10 \mathrm{~ns}$ \\
\hline
\end{tabular}

Values are expressed as mean \pm SD $\left(\mathrm{n}=3\right.$ /group). ${ }^{* *} \mathrm{p}<0.001 ;{ }^{* *} \mathrm{p}<0.01 ;{ }^{*} \mathrm{p}<0.05 ; \mathrm{ns} \mathrm{p}>0.05$ compared to the control group. ALT: alanine amino-transferase, AST: aspartate amino-transferase, CHOL: Cholesterol, GLU : Glucose, ALP: alkaline phosphatase. 
Biochemical examination was performed in order to evaluate any toxic effects on liver, kidney, and glucose metabolism. The parameters such as aspartate aminotransferase, alanine aminotransferase, alkaline phosphatase glucose and cholesterol were examined. It is known that the liver and kidneys play significant roles in various metabolic processes. The liver plays an important role in xenobiotic function; and the kidneys are the main organs involved in drugs elimination and therefore, particularly exposed to the toxic effects of exogenous compounds 11 .

Serum enzymes like AST, ALT and ALP are well-known enzymes used as good indicators of liver function 12 and as biomarkers predicting possible toxicity ${ }^{13}$. Both AST and ALT are sensitive markers of acute hepatocellular injury and are routinely used to identify liver disease 14 . AST which was formerly known as serum glutamic oxaloacetic transaminase (SGOT), is found in both cytosol and mitochondria in several organs such as the liver, cardiac muscle, skeletal muscle, kidney, brain, pancreas, lung, leukocytes, and erythrocytes but the concentration is highest in the hepatic parenchyma. On the contrary, ALT (formerly serum glutamic pyruvic transaminase or SGPT) is a cytosolic enzyme which is present predominantly in the liver. Hence ALT is a more specific indicator of liver injury than AST. Serum levels of these enzymes reflect injury of the concerned organs especially the liver 15. Moreover, serum ALP activity increases in case of damage to the hepatic cells and obstruction of the bile ducts 16 . The results of the present study showed that the value of AST and ALT concentrations in groups treated with aqueous leaves and flowers extract of Thymelaea hirsuta at a dose of 4, 5.5 and $7 \mathrm{~g} / \mathrm{kg}$ body weight for 7 days by oral route were significantly increased compared to control.

The liver is a metabolically active organ that utilizes carbohydrates for synthesis of cholesterol and fatty acids, stores glucose as glycogen and free fatty acids as triglycerides (TG). The liver plays a critical role in maintaining blood glucose levels during fasting by synthesis of glucose from amino acids (gluconeogenesis) and releasing glucose from glycogen (glycogenolysis). The liver absorbs fat (TG) and cholesterol from the diet and synthesizes fatty acids and cholesterol from acetyl-CoA derived from glucose. The liver catabolizes cholesterol to bile acids, which facilitate biliary secretion of cholesterol and intestinal absorption of dietary fats and cholesterol ${ }^{17}$. As a significant decrease were observed in glucose and cholesterol levels in this study, this suggests that Thymelaea hirsuta aqueous extract had an effects on the lipid and carbohydrate metabolism.

\section{CONCLUSION}

Results from this study indicated that oral administration of Thymelaea hirsuta aqueous extract at a dose up to $7 \mathrm{~g} / \mathrm{kg}$ b.wt, did not produce any mortality. However, from the blood analysis, it showed that aqueous leaves and flowers extract of Thymelaea hirsuta may cause increase in AST and ALT and decrease in glucose and cholesterol. However, the preliminary results suggested that it should be further evaluated for long term use and repeated dose effects to ensure safety of this herb.

\section{REFERENCES}

1. Verma SK and Kumar A. Therapeutic uses of Withania somnifera (Ashwagandha) with a note on withanolides and its pharmacological actions. Asian Journal of Pharmaceutical and Clinical Research. 2011; 4:1-4.

2. Gesler WM. Therapeutic landscapes: medicinal issues in light of the new cultural geography. Social Sci Med. 1992; 34:735-746.

3. Bent $\mathrm{S}$ and Ko R. Commonly used herbal medicines in the United States: A review. Am J Med. 2004; 116:478-485.

4. Badawya AM, Hassanean HA, Ibrahim AK, Habib ES, Ahmed SA Review article on chemical constituents and biological activity of Thymelaea hirsuta. Rec. Pharm. Biomed. Sci. 2019; 3(2):2832.

5. Kawano M, Matsuyama K, Miyamae Y, Shinmoto H, Kchouk ME, Morio T, Shigemori H, Isoda H. Antimelanogenesis effect of Tunisian herb Thymelaea hirsuta extract on B16 murine melanoma cells. Exp Dermatol. 2007; 16(12):977-984.

6. Villareal MO, Han J, Yamada P, Shigemori H, Isoda H. Hirseins inhibit melanogenesis by regulating the gene expressions of Mitf and melanogenesis enzymes. Exp. Dermatol. 2010; 19(5):450-7.

7. Djeridane A, Yousfi M, Nadjemi B, Boutassouna D, Stocker P, Vidal N. Antioxidant activity of some Algerian medicinal plants extracts containing phenolic compounds. Food Chem. 2005; 97:654-660.

8. Bnouham M, Merhfour FZ, Legssyer A, Mekhfi H, Maâllem S, Ziyyat A. Antihyperglycemic activity of Arbutus unedo, Ammoides pusilla, and Thymelaea hirsuta. Pharmazie. 2007; 62(8):630-632.

9. Miyamae Y, Villareal MO, Abdrabbah MB, Isoda H, Shigemori H Hirseins A and B, daphnane diterpenoids from Thymelaea hirsuta that inhibit melanogenesis in B16 melanoma cells. J Nat Prod. 2009; 72:938-41.

10. Frank CLU. 1992. Toxicologie, Données générales, procédures d'évaluation, organes cibles, évaluation du risque. Paris.

11. Bidhe RM and Ghosh S. Acute and subchronic (28 days) oral toxicity study in rats fed with novel surfactants. The AAPS Journal. 2004; 6:1-10.

12. Rahman MF Siddiqui MK and Jamil K. Effects of Vepacide (Azadirachta indica) on aspartate and alanine aminotransferase profiles in a subchronic study with rats. Human and Experimental Toxicology. 2001; 20:243-249.

13. Mdhluli M. 2003.Toxicological and antifertility investigations of oleanolic acid in male vervet monkeys (Chlorocebus aethiops).PhD Thesis.Discipline of Physiological Sciences, University of the Western Cape, Cape Town, South Africa. PathCare, 2009.Laboratory Manual. Parow, Cape Town, South Africa.

14. karmen A, Wroblewski F, Ladue JS. Transaminase activity in human blood. J Clin Invest. 1955; 34:126-131.

15. Kallai L, Hahn A, Roeder V, Županic V. Correlation between histological findings and serum transaminase values in chronic diseases of the liver. Acta Medica Scandinavica. 1964; 175:4956.

16. Akhtar A, Deshmukh AA, Raut CG, Somkuwar AP and Bhagat SS Prallethrin induced serum biochemical changes in Wistar rats. Pesticide Biochemistry and Physiology. 2012 ; 102:160-168.

17. Chiang J.. Liver Physiology: Metabolism and Detoxification Pathobiology of Human Disease. 2014 ; 1770-1782. 